\title{
Vascular System
}

National Cancer Institute

\section{Source}

National Cancer Institute. Vascular System. NCI Thesaurus. Code C33854.

The cardiovascular and lymphatic systems, collectively. 